\title{
Interdisciplinaridade no Ensino Superior: uma experiência na licenciatura em Educação Básica
}

\begin{abstract}
Carla Guerreiro $^{a}$, Paula Fortunato Vaz ${ }^{\text {, }}$, João Gomes ${ }^{c}$, Marco Costa ${ }^{\text {d }}$
anstituto Politécnico de Bragança, Campus de Santa Apolónia, 5300-253 Bragança, Portugal, Instituto de Estudos de Literatura e Tradição, carlaguerreiro@ipb.pt, ${ }^{b}$ Centro de Investigação em Educação Básica, Instituto Politécnico de Bragança, Campus de Santa Apolónia, 5300-253 Bragança, Portugal, paulavaz@ipb.pt, ${ }^{\mathrm{C} I n s t i t u t o ~ P o l i t e ́ c n i c o ~ d e ~ B r a g a n c ̧ a, ~ C a m p u s ~ d e ~ S a n t a ~ A p o l o ́ n i a, ~ 5300-253 ~}$ Bragança, Portugal, jogomes@ipb.pt, ${ }^{\mathrm{d}}$ Instituto Politécnico de Bragança, Campus de Santa Apolónia, 5300-253 Bragança, Instituto de Investigação em Arte, Design e Sociedade, marcocosta@ipb.pt.
\end{abstract}

\section{Resumo}

Nesta comunicação, apresentamos resultados de uma experiência implementada no 2. ${ }^{\circ}$ ano da Licenciatura em Educação Básica (LEB) de uma instituição de Ensino Superior do Nordeste de Portugal, que teve como objetivos: (i) promover a articulação e a interdisciplinaridade entre duas unidades curriculares (UCs) desta licenciatura e, consecutivamente, o desenvolvimento de competências transversais a ambas, através de um trabalho conjunto dos estudantes e dos docentes envolvidos; (ii) perceber de que forma os alunos envolvidos avaliam este tipo de articulação entre diferentes unidades curriculares. Tendo por base a obra literária de potencial receção infantojuvenil de Richard Zimmler intitulada: "Maria e Danilo e o mágico perdido”, os alunos envolvidos, num primeiro momento leram, interpretaram e transformaram em texto dramático o texto narrativo original. Posteriormente, encenaram-no e apresentaram-no à comunidade. No final os alunos da LEB avaliaram a sua perceção desta experiência de articulação entre as UCs. Apresentamos os resultados preliminares, obtidos a partir dos dados analisados, resultantes das ações reflexivas, exploratórias, formativas e expressivas trabalhadas com os alunos diretamente envolvidos.

Palavras-chave: Interdisciplinaridade, Licenciatura em Educação Básica, literatura infantojuvenil, expressão dramática. 


\section{Enquadramento}

Os dados da literatura pesquisada demonstram que a interdisciplinaridade pode auxiliar na dissociação do conhecimento produzido e orientar a produção de um novo tipo de conhecimento, constituindo condição necessária para a melhoria da qualidade do Ensino Superior, mediante a superação da fragmentação, uma vez que orienta a formação holística do ser humano. Desenvolver a interdisciplinaridade no Ensino Superior requer profundas mudanças na vida académica, abrindo espaços efetivos para a prática da iniciação científica, da pesquisa e da interação. Essas mudanças passam pela articulação dos currículos das Unidades Curriculares (UCs) existentes a nível do plano curricular dos cursos de licenciatura, modificando de forma essencial o papel do professor no contexto educativo (Favarão \& Araújo, 2004).

A vivência de aprendizagens interdisciplinares em artes, explorando diferentes formas de criação e realização de projetos, incluindo a prática de investigação, encontra-se referenciada no documento orientador das práticas artísticas no Ensino BásicoCompetências Essenciais (2001), documento esse que destaca a importância das linguagens artísticas no desenvolvimento da criatividade, capacidade de expressão e comunicação, sendo necessário, para o efeito, que essa relação se estabeleça também em contexto.

As disciplinas artísticas são absorventes da cultura e posicionam-se criticamente sobre ela, o que leva que o artista crie representações de si e do outro. Por este modo, a arte ajuda a construir uma consciência da multiplicidade, da diferença e da liberdade individual, atitudes estas, benéficas à inclusão. É tácito afirmar que os vários campos artísticos defendem o pluralismo na busca da verdade do mundo pela expressão individual, assumindo a ideia dos múltiplos olhares sobre a realidade. Através da imaginação e da representação simbólica, o individuo recria a imaterialidade da vida em formas sensíveis, plausíveis de comunicabilidade e portanto, geradoras de significados. Esta dupla vertente da arte (reflexiva e comunicativa) ajuda à percepção e desenvolvimento da identidade por via da consciência da expressão pessoal aplicada na obra. Através dos métodos de concetualização, concreção e recepção da obra, gera-se um confronto entre o "eu" e o "outro" que se ameniza por meio da necessidade de exposição e pela possibilidade de contemplação da obra. Esta forma de respeito das partes, é em si uma forma de inclusão sócio-cultural.

A participação das comunidades educativas nas culturas locais, para além do estímulo às aprendizagens ativas, promove o interesse pela diversidade cultural (Roteiro para a Educação Artística, 2006), o que acentua a importância da preservação das identidades, dos valores pessoais e coletivos, através dum ensino criativo que desenvolva a perceção, a criatividade e a iniciativa, a reflexão crítica e a capacidade profissional. 
Maréchal (1989) considera que no campo da formação de professores se deve promover o contacto com diferentes modelos de práticas dramáticas, criando condições para que os participantes possam experimentar diversas perspetivas de abordagem das mesmas, experienciando as particularidades de cada uma delas.

A «mise en action», de acordo com Maréchal (1989), é constituída por um grupo de práticas de natureza ludo-expressiva, que se caraterizam pelo incentivo à implicação individual e coletiva do participante (enquanto pessoa). A «dramatização» é um modelo que se refere às atividades dramáticas de jogo/improvisação que se orientam para a criação de uma ficção (verbal e não verbal), tomando geralmente a forma de um projeto espontâneo e imediato.

As práticas relativas à «teatralização», como refere Maréchal (1989), desenvolvem-se através da dinâmica que existe entre a criação de uma ficção e a sua realização (produção de um espetáculo), de acordo com diferentes contextos de representação, propostas de encenação e condições materiais de produção.

De natureza interdisciplinar (a decorrer no ano de 2019), resultando de uma articulação entre as UCs da Licenciatura em Educação Básica (LEB), Literatura Infantojuvenil e Expressão Dramática, e destas com a comunidade, mais concretamente, com uma IPSS da cidade de Bragança, o projeto " Literatura infantojuvenil na promoção de uma Educação Inclusiva" teve por objetivo trabalhar o tema "Diferenças(s)", com vista à promoção de uma Educação Inclusiva, articulando diferentes instituições e cursos de Licenciatura da Escola Superior de Educação (ESE) do Instituto Politécnico de Bragança (IPB).

Partiu-se da obra de potencial receção infantojuvenil Maria e Danilo e o mágico perdido de um dos mais relevantes escritores da atualidade, Richard Zimmler, para desenvolver um conjunto de ações articuladas quer com os alunos da ESE-IPB dos cursos envolvidos, quer com a instituição parceira (para além da LEB também a licenciatura em Arte e Design foi envolvida).

Assim, entre outros, um dos objetivos centrais do projeto foi o de promover a articulação e a interdisciplinaridade entre Unidades Curriculares da LEB, e assim, o desenvolvimento de competências transversais a ambas as UCs, através de um trabalho conjunto quer dos estudantes, quer dos docentes envolvidos. Para além deste pretendeu-se perceber de que forma os alunos envolvidos avaliam este tipo de articulação entre diferentes UCs. 


\section{Procedimentos e opções metodológicas}

O trabalho desenvolvido teve início com a seleção, leitura, análise e reflexão crítica da obra literária, seguidas da sua adaptação à linguagem teatral e posterior apresentação a crianças do 1..$^{\circ}$ e do 2..$^{\circ}$ Ciclo do Ensico Básico (CEB), que durante alguns meses também trabalharam a obra e realizaram trabalhos escritos acerca da mesma. No dia da apresentação às crianças realizou-se um seminário aberto à comunidade, com a presença do ilustrador da obra selecionada, com a exposição em simultâneo dos trabalhos realizados pelos alunos do 1. ${ }^{\circ}$ e 2. ${ }^{\circ}$ CEB da IPSS. No contexto da unidade curricular de Expressão Dramática promoveu-se o desenvolvimento e a aplicação de conhecimentos no domínio da educação estética e artística, utilizando para o efeito a linguagem dramática como meio de expressão/comunicação e criação/produção, concretizando todo esse processo através da realização de peças de teatro dirigidas ao público infantil. No âmbito da unidade curricular de Literatura Infantojuvenil, os alunos leram, interpretaram e fizeram a transformação do texto literário de Richard Zimmler para texto dramático.

Para aferir o grau de satisfação dos discentes envolvidos no projeto e as suas sensibilidades, utilizou-se uma pesquisa de campo de cariz qualitativo e quantitativo, através do uso de um inquérito por questionário semi-estruturado, disponibilizado em suporte de papel. A amostra é constituída pelos vinte e dois alunos que frequentavam o $3 .^{\circ}$ ano da Licenciatura de Educação Básica e que frequentaram as unidades curriculares: Literatura Infantojuvenil e Expressão Dramática.

\section{Apresentação e análise dos resultados}

Apresentamos, seguidamente, o resultado do questionário, com base nas respostas dadas pelos alunos dinamizadores do projeto.

Perante a afirmação a) "No Ensino Superior, normalmente, os professores não trabalham interdisciplinarmente": $19 \%$ responderam concordo totalmente; 26\%-responderam concordo, $40 \%$ responderam concordo parcialmente e $15 \%$ responderam discordo.

Relativamente à afirmação b) "É uma mais-valia para a construção de conhecimento desenvolver trabalho cooperativo, juntando-se duas ou mais áreas disciplinares": 53,8\% responderam concordo totalmente, $26,9 \%$ responderam concordo; $11,5 \%$ responderam concordo parcialmente e $7,7 \%$ responderam discordo. 
Quanto à afirmação c) "O Projeto desenvolvido possibilitou um melhor conhecimento das artes cénicas da representação": $57,7 \%$ concordaram totalmente; 34,6\% concordaram e 7,7 concordaram parcialmente.

Na questão d) “ Teria sido mais fácil trabalhar a obra literária sugerida em Literatura Portuguesa, se não tivesse havido articulação com a área de Expressão Dramática?”: 15,4\% discordaram totalmente, 57,7\% discordaram, 19,2\% concordaram parcialmente e apenas $7,7 \%$ concordaram;

Na pergunta e) “ Teria sido mais enriquecedor que a nível da Expressão Dramática, os alunos não tivessem tido sugestões de leitura em Literatura Portuguesa?" 19,2\% discordaram totalmente; $69,2 \%$ discordaram e apenas $11,5 \%$ concordaram parcialmente.

À questão: f) "Acha que a experiência vivida lhe proporcionou condições para o desenvolvimento das capacidades de improvisação, dramatização e interpretação, de resolução de problemas"? $88,5 \%$ dos inquiridos responderam afirmativamente e apenas $11,5 \%$ deram uma resposta negativa.

À pergunta g) "O corpus textual de Literatura Portuguesa, que serviu como base de trabalho, foi-lhe apresentado pela docente. Concorda com esta forma de trabalho?" $88,5 \%$ dos questionados responderam afirmativamente, tendo respondido negativamente apenas $11,5 \%$.

\section{Considerações Finais}

Com base na apreciação final deste projeto, manifestada pelos alunos logo após a sua realização, com base no questionário disponibilizado concluímos que o projeto é referenciado como sendo uma experiência muito exigente e enriquecedora, dada a interdisciplinaridade e a complexidade das áreas abrangidas: interpretação e adaptação de textos, conceção estética e artística do espetáculo. Note-se que quase metade dos inquiridos referiu que no Ensino Superior, normalmente, os professores não trabalham interdisciplinarmente e cerca de $80 \%$ concordam/concordam totalmente que o trabalho cooperativo entre duas ou mais áreas disciplinares é uma mais-valia para a construção de conhecimento. Acresce-se o facto de $73,1 \%$ dos alunos discordarem/discordarem totalmente de que teria sido mais fácil trabalhar a obra selecionada sem a articulação interdisciplinar e de $88,5 \%$ considerarem que a experiência vivida lhes proporcionou condições para o desenvolvimento das capacidades de improvisação, dramatização e interpretação e de resolução de problemas. 
Outro aspeto referido foi a dinâmica de grupo desencadeada com uma ação desta natureza, visto que, a realização de tarefas multifacetadas exige uma grande capacidade de organização, tendo gerado neste contexto uma interação acrescida entre os intervenientes, espírito de entreajuda e confraternização entre elementos do mesmo grupo e da turma em geral.

Destaca-se também por parte dos alunos da LEB o reconhecimento da importância de todo o processo intrínseco à apresentação de uma peça de teatro: os diferentes conceitos de espetáculo, a preocupação com os detalhes como essenciais à criação do todo e que é através dos ensaios que se percebe a união de todos esses elementos e entende a qualidade do que se apresenta, o que se nos afigura muito positivo em termos de experiência.

A capacidade de interpretação é considerada muito importante na medida em que se aprende a contar histórias, a desempenhar papéis de diferentes personagens, colocando-se o desafio na melhor forma de interpretação e adaptação da obra escolhida.

A capacidade de resolução de problemas é também considerada uma aprendizagem fundamental dado que os trabalhos foram realizados em grupo, o que exige esforço de cooperação. Os alunos revelaram-se mais motivados para próximas encenações e destacaram, neste processo, o apoio disponibilizado pelos docentes no conjunto dos trabalhos efetuados.

Como aparece referido pelos alunos, a experiência contribuiu para a construção de conhecimentos e habilidades que se vão repercutir futuramente na prática profissional, relacionando diferentes áreas do saber. Ficaram também sensibilizados com a possibilidade de desenvolver uma comunicação mais eficaz junto dos seus destinatários.

Não é alheio neste processo o que significa trabalhar em equipa, através da partilha de ideias e trabalhos conjuntos que se traduziram na construção de um objeto artístico comum. Foi, de fato, um fator de agregação de todos seus intervenientes e um exemplo de ensino/aprendizagem colaborativo.

\section{Referências}

Favarão, N. \& Araújo, C. (2004). Importância da interdisciplinaridade no ensino superior. Educere, v. 4, n. 2, p. 103-15.

Maréchal, A. (1989) L'interaction entre formation et intervention dans les pratiques d'animation et de création en art dramatique, Rapport présenté au Colloque Franco Québecois ArtEducation, Paris. 
Ministério da Cultura e Ministério da Educação (2000). A educação artística e a promoção das artes na perspectiva das políticas públicas. Lisboa: Relatório do grupo de contato entre os Ministérios da Cultura e da Educação.

UNESCO, (2006). Roteiro para a Educação Artística: Desenvolver as Capacidades Criativas para o Século XXI. Lisboa: Comissão Nacional da UNESCO. 